\title{
Retraction Note: Effects of boundary slippage on thin-film lubrication between two nonparallel plane plates
}

\author{
Shu-Hao Ban · Xiao-Yan Li
}

(C)The Chinese Society of Theoretical and Applied Mechanics and Springer-Verlag Berlin Heidelberg 2012

Retraction to: Acta Mechanica Sinica (2012) 28(3):625-630 DOI 10.1007/s10409-012-0086-7
This article is retracted at the request of the Editor-inChief and the author due to copyright issues concerning all the research data, theory, method and conclusion.

The online version of the original article can be found under doi 10.1007/s10409-012-0086-7.

S.-H. Ban (凶) X.-Y. Li

College of Mechanical and Energy Engineering,

Changzhou University, 213016 Changzhou, China

e-mail: banshuhao@tsinghua.org.cn 